\title{
Through the client's eyes - service delivery is critical
}

\author{
BY DANA COOPER
}

Y ou thought you were in the optometry business. In fact, whether you like it or not, you are in the client service business. Regardless of what your business model looks like now or how it will change in the future, one constant will always remain you are reliant on repeat clients to survive.

Another reality is that clients' needs can be fulfilled by many businesses in addition to yours. There are other providers who can perform eye health examinations or provide brand name corrective eyewear that satisfy the needs of the clients. How you provide service to your clients is what makes you unique. You and your team will need to exploit this uniqueness.

You can break down the client service into two critical elements: the tangible, and the emotional. The tangible relates to the product or service you provide to your client. The emotional involves the interactions you have with your clients in providing that product or service, or the client experience.

Your business will be evaluated on both - the degree to which your products and services satisfy the underlying need, and how pleasurable and satisfying the client experience is for them. However, it will be the client experience that clients will remember most, and will be a primary determinant as to if they come back again. Even the best products can be overcome by a shoddy experience. In other words, bad service can taint the entire organization.

If you want to ensure your current clients have regular eye health examinations or ensure they do not buy glasses or contacts from the internet, then you must give them a reason. That reason needs to be you and your team. Human beings are social animals and want to develop relationships that help them to satisfy their needs. People change service providers because they are dissatisfied with the relationship they have with their existing service provider. Clients are literally yours to lose!

What about price? If you do not excel at differentiating the experience people have interacting with your business, then price will be all that matters to clients. However, if you can engage the clients, develop trust, and provide a pleasurable experience, price will definitely be secondary.

Providing an experience that is intended to build a relationship with the client is the key. What we are talking about here is not a system or a strategy - it is an attitude - a genuine and sincere desire to provide exceptional service quality to all clients. With that attitude comes a long term perspective of the lifetime value of the customer that drives strategy to engage the clients.
For instance, consider a computer retailer. A computer store would be leaving a considerable opportunity on the table if they just considered clients in terms of a computer sale. To be successful, they should be embracing clients in terms of their future needs for service, a buyer of peripherals, software, computer upgrades, etc. Knowing that people typically look to upgrade every three years, computer stores will obtain a high percentage of repeat business, if they initiate communication with the client after three years, and if the initial experience for the client was good. This opportunity is only available if the initial customer experience was positive. Make it easy for the client to continue the relationship.

Optometrists have these same opportunities. Repeat service reminders to clients whose last eye examination was $1 \frac{3 / 4}{4}$ years ago would earn a greater number of repeat examination clients than if a reminder was not provided. A frame sale would be of interest to customers who purchased glasses three or more years ago. There is a multitude of similar opportunities right in front of you that you can define and provide to clients that will be a valuable and appreciated service. Can your database do this? 


\section{'Know Your Customers' equals 'Build Relationships'}

There are few things more powerful to the client than to be recognized and referred to by name. Over time it can become fairly easy to recognize repeat clients. For those who are not recognizable yet, optometrists have an advantage as much of their business is by appointment, so an educated guess as to who is walking through the door at a given moment will likely be successful. Even if that is not doable, after giving their name and calling up their record on the database it should be easy for a team member to see their history with the business and engage in conversation such as, "How are those new contact lenses working for you?".

Your database is a critical component to being able to personalize your service to your clients. It tells you who they are, what they need from you, how valuable they are to your business, and what you can do for them. The more personal we can make the service experience the more successful we will be at building relationships.

Anytime you can use a client's name, talk to them about their experience with the company or differentiate them from the pack, they will remember and appreciate your efforts. Little things such as this go a long way to developing the type of relationship you are looking for with your clients.

\section{Similar Basic Needs of All Customers}

While the quality of a client experience is defined by individual perceptions, we can identify similar basic needs which all clients possess and that can have a dramatic impact on the quality of client experience you provide. Ask yourself these questions:

- What are we doing to make clients feel welcome? How can we greet them warmly?

What can we do to ensure that our clients feel important?

How can we show them that satisfying their needs is a role we take seriously?

- How can we make clients feel comfortable? (In store, on the phone, on our website.)

Is there something we can do better, so that our clients feel listened to and understood?

- What will you do for that client to indicate you appreciate their business?

\section{Indifference is Death}

Quality service delivery does not mean perfect service delivery. Mistakes are going to happen. The reality is though, problems arise

\section{Elements to Exceptional Service}

You will be evaluated on 2 key factors to customer service:

- Tangible: this is the product or service that can satisfy the need of the client (vision examination, corrective eyewear, etc.)

- Emotional: how pleasurable and satisfying the client service experience was

not because mistakes happen, but rather how the service provider reacts to those mistakes. Indifference is death!

Client service satisfaction is increased exponentially if problems are dealt with promptly and efficiently. Staff must be empowered to deal with service issues as they arise. It will be considerably more expensive to lose a client (and replace that client with a new one) than it will be to train and empower staff on overcoming service failures and providing them with the latitude it takes to present superior client experience. This is again part of the attitude that goes along with being a breakthrough service organization.

A study by McKinsey and Company indicated that clients whose complaints are properly dealt with may become more loyal than those who have never experienced problems. This does not suggest 


\section{A client's intention to repurchase doubles from 9 to $19 \%$ simply by having a forum to complain. 99}

that you should intentionally create problems to solve for your clients. However, the organization's eagerness to solve a problem and improve performance builds the client's trust and translates into future business.

\section{No Time for Complacency}

If you do not hear any client service complaints do not assume that everything is alright. Clients will not complain $96 \%$ of the time. For every complaint that is heard there are 26 more that you do not hear about! Of those, six are serious. Studies indicate that $90 \%$ of clients who have experienced a problem do not return - that is unless you had a relationship with them (Retail Council of Canada). That is one of the values of having a relationship with your customers - forgiveness.

If there is a problem with the client experience you are providing, you want to know about it. The problem, as noted above, is that people avoid mentioning when they do have a problem. Conflict avoidance is typical human nature. It should be an expressed priority for your business to hear from your clients when they have good and bad things to say. You need to find some way to make it easy for clients to tell you what they are thinking.
More clients will walk through the door if you open it for them. What this means is, that if you make a sincere inquiry with the client such as, "Were you satisfied with your visit with us today?", you will get sincere feedback from them. This question will elicit a 'yes' or 'no' response. A 'no' response should be queried further. A 'yes' response can be followed-up with, "Was there anything more we could have done today to make your visit more pleasurable?". This last follow-up is intended to be a second query to elicit information from the customer and may also provide valuable information.

A few important points about client feedback should be made. First, make sure it is recorded in the database, or written down as the customer provides it. Secondly, use the information to improve the client experience your business provides. If you start to see multiple mentions of similar problems - take action. The best client experience businesses would do this and would also follow-up with the clients to tell them how their feedback helped the business.

Finally, do everything you can to avoid stock questions that are anything but sincere such as the "How are you today?" or "May I help you?" genre of questions. It is difficult to be sincere when you are the same as $97 \%$ of the service businesses people experience regularly. Engage the clients with sincerity that expresses an interest to connect. If you show genuine interest, more often than not the client will return the sentiment.

\section{Bottom Line}

Every encounter with a client, whether face-to-face, on the phone, via mail, or on the internet, is an opportunity to further develop that relationship and ensure they return for another visit. It is an opportunity to get feedback from them, and also an opportunity for you to show you care about them and appreciate their trust.

Great service is a genuine interest and desire to effectively satisfy the needs of the client in a pleasurable and enjoyable manner. It is an attitude. It is little things like smiling, eye contact, and listening that show you care - these things make a huge difference to people in general and an even larger difference to your clients.

Satisfying the need the client comes to you with is a very minor aspect of how you will be evaluated as a business. The journey to fulfilling that need is where the clients' perceptions will focus. Adding warmth and pleasure to the experience, makes you a business people want to have a relationship with. 